\title{
The role of benign joint hypermobility in the pain experience in Juvenile Fibromyalgia: an observational study
}

Tracy V Ting ${ }^{1 *}$, Philip J Hashkes ${ }^{2}$, Kenneth Schikler ${ }^{3}$, Anjali M Desai ${ }^{4}$, Steven Spalding ${ }^{5}$ and Susmita Kashikar-Zuck ${ }^{4}$

\begin{abstract}
Background: Juvenile Fibromyalgia (JFM) is characterized by chronic widespread musculoskeletal pain and approximately $40 \%$ of children and adolescents with JFM also suffer from benign joint hypermobility (HM). It is not currently known if the presence of HM affects the pain experience of adolescents with JFM. The objective of this study was to examine whether there were any differences in self-reported pain intensity and physiologic pain sensitivity between JFM patients with and without joint HM.

Methods: One hundred thirty-one adolescent patients with JFM recruited from four pediatric rheumatology clinics completed a daily visual analogue scale (VAS) pain rating for one week and underwent a standardized 18-count tender point (TP) dolorimeter assessment. Medical records were reviewed for the presence of joint HM. Average pain VAS ratings, tender point count and tender point sensitivity were compared between JFM patients with and without hypermobility ( $\mathrm{HM}+$ and $\mathrm{HM}-$ ).

Results: Nearly half (48\%) the sample of JFM patients were found to be HM+. HM+ and HM- patients did not differ in their self-reported pain intensity. However, $\mathrm{HM}+$ patients had significantly greater pain sensitivity, with lower TP thresholds $(p=0.002)$ and a greater number of painful TPs $(p=0.003)$ compared to HM- patients.

Conclusion: The presence of HM among adolescent patients with JFM appears to be associated with enhanced physiologic pain sensitivity, but not self-report of clinical pain. Further examination of the mechanisms for increased pain sensitivity associated with HM, especially in adolescents with widespread pain conditions such as JFM is warranted.
\end{abstract}

Keywords: Juvenile fibromyalgia, Hypermobility, Tender point, Pediatric, Pain

\section{Background}

Juvenile fibromyalgia (JFM) is a chronic condition of widespread musculoskeletal pain and fatigue in children and adolescents. Prevalence estimates for JFM range from $1-6 \%$ of the pediatric population $[1,2]$. While there are often associated symptoms of poor sleep, fatigue, and emotional distress in JFM, pain is the defining component in the diagnosis of fibromyalgia (FM). The report of diffuse pain for 3 or more months and severe pain in multiple tender points upon palpation is required as part of the classification criteria for FM by both Yunus and

\footnotetext{
* Correspondence: tracy.ting@cchmc.org

'Division of Rheumatology, MLC 4010, Cincinnati Children's Hospital Medical Center, 3333 Burnet Avenue, Cincinnati, OH 45229, USA Full list of author information is available at the end of the article
}

Masi [3] and the 1990 American College of Rheumatology (ACR) [4] criteria.

Benign joint hypermobility (HM) is a relatively more common condition than JFM, with prevalence rates in children and adolescents estimated to be up to 30\% [5]. Children and adolescents with increased joint laxity have been found to frequently suffer from chronic musculoskeletal pain complaints [5,6], although one large population study indicated no such association [7]. Yet many children with joint HM do not suffer from the full spectrum of JFM symptoms. On the other hand, there appears to be a much closer overlap among patients with JFM and benign joint HM. In fact, two studies have reported a higher prevalence of HM co-occurring with JFM. One study found that $81 \%$ of Israeli JFM school-

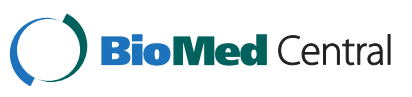

(c) 2012 Ting et al.; licensee BioMed Central Ltd. This is an Open Access article distributed under the terms of the Creative Commons Attribution License (http://creativecommons.org/licenses/by/2.0), which permits unrestricted use, distribution, and reproduction in any medium, provided the original work is properly cited. 
children had HM [8], and another study based in the United States reported that $40 \%$ of JFM adolescents also had HM [9]. In the adult literature, it has been suggested that the presence of $\mathrm{HM}$ is associated with increased pain in women with FM [10]. However, the relationship between pain characteristics and HM has not been examined in children and adolescents with JFM.

The underlying mechanisms for pain hypersensitivity in FM have been extensively studied while the etiology of pain in HM has received little attention. It has been well documented that persons with FM have an overall lower threshold for pain as demonstrated by increased responsiveness and hypersensitivity to pain [11] in the form of central sensitization and wind-up in response to repeated noxious stimulation [12]. It is not currently known whether joint laxity/HM is associated with enhanced sensitization to pain in FM although it has been suggested (though not proven) that repeated microtrauma occurring among persons with abnormal joint hyperextensibility might lead to persistent localized pain [13].

As part of the screening for a larger clinical trial examining the effectiveness of cognitive-behavioral therapy for JFM, we assessed baseline pain intensity and tender point sensitivity (tender point count and tender point threshold) of over 100 adolescents with JFM [14]. For the current study, we reviewed patients' medical charts to determine the frequency of benign joint HM as determined by their treating rheumatologist. The primary objectives of this study were to examine the prevalence of HM in this clinical sample of adolescents with JFM and to compare the pain experience between JFM patients with joint $\mathrm{HM}(\mathrm{HM}+)$ and without (HM-). Based upon previous studies, it was anticipated that at least $40 \%$ of JFM patients would be $\mathrm{HM}+[2,5,6,15]$. We also hypothesized that JFM patients who were $\mathrm{HM}+$ would report higher clinical pain intensity (based upon self-report) and demonstrate enhanced pain sensitivity (based upon dolorimetry) compared to those who were HM-.

\section{Methods}

\section{Participants}

Participants were 131 adolescents (92.4\% female, 89.3\% Caucasian) with JFM between the ages of 11 and 18 years (mean age $=15.1$ years) who were initially screened for the parent clinical trial. Participants were recruited from four pediatric rheumatology clinics (six total pediatric rheumatologists) in Ohio and Kentucky, with each site having Institutional Review Board approval. All participants met Yunus and Masi criteria [3] adapted for JFM classification which includes: generalized musculoskeletal aching for greater than three months, the presence of at least 5 out of 18 tender points, and at least three associated symptoms such as poor sleep quality, fatigue, chronic anxiety, irritable bowel syndrome or chronic headaches. Participants had to have an average pain intensity of at least 4 (on a $0-10 \mathrm{~cm}$ visual analog scale, VAS) to be eligible for the trial and were excluded if they had other chronic rheumatic diseases such as juvenile idiopathic arthritis or systemic lupus erythematosus or other comorbid illness that could cause fibromyalgia-like symptoms (e.g. thyroid disease).

\section{Procedure}

Participants were informed of the study by their primary rheumatologist and contacted by a research assistant for their interest in participation. Written informed consent from parents and assent from adolescents was obtained. Participants were asked to complete a daily pain diary for the week prior to the initial evaluation. All participants were formally evaluated by a pediatric rheumatologist with a complete medical history and physical examination.

\section{Measures}

\section{Demographic information}

A demographic form regarding the participant's age, sex, race and ethnicity was completed by the parent(s).

\section{Tender point assessment (pain sensitivity)}

An 18-count TP examination, as described in the ACR criteria for FM [4], was performed by a trained pediatric rheumatologist. A dolorimeter (Pain Diagnostics \& Treatment Inc., Great Neck, NY) with a $1 \mathrm{~cm}$ rubber tip was applied at a rate of $1 \mathrm{~kg} / \mathrm{cm}^{2}$ of pressure per second. The participant was asked to inform the evaluator the point at which pain (not pressure) was felt and this pain threshold, from 1 to $>4 \mathrm{~kg} / \mathrm{cm}^{2}$, was noted for each of the 18 TP sites. An average TP score (pain threshold) based upon the 18 points was calculated, with lower scores indicating greater pain sensitivity. The total number of positive (score of $<4 \mathrm{~kg} / \mathrm{cm}^{2}$ ) painful TPs was also recorded.

\section{Pain rating (VAS)}

For one week prior to their assessment visit, adolescents completed a diary rating of their average level of pain each day using a Visual Analog Scale (VAS, $10 \mathrm{~cm}$ horizontal line with no numerical markings). VAS scales [16] are well-validated and widely used in pediatric pain research [17]. The pain VAS scale was anchored with the descriptors of $0=$ "no pain" and $10=$ "worst possible pain". The average pain rating over the period of one week of daily diaries was used as a measure of selfreported clinical pain intensity. 


\section{Medical chart review}

Medical charts were reviewed for participant information regarding physical exam findings, including joint HM. HM was defined by each individual clinician's assessment of increased joint laxity (HM noted to be present if found in at least 4 joints). For this preliminary clinical observational study, information about specific standardized criteria for HM (such as Beighton scores) was not available due to variability in clinical documentation in medical records at each site. However, all examining physicians were board certified/eligible pediatric rheumatologists who are trained to use similar criteria for classification of HM in children. Each of the 6 pediatric rheumatologists indicated they used either the Beighton [18] or Carter and Wilkinson [19] criteria (Table 1) for joint hypermobility and documented hypermobility if they met criteria.

\section{Statistical analyses}

All data were entered and analyzed using SPSS Version 15.0 software. Descriptive data on pain VAS scores,

Table 1 Criteria for Joint Hypermobility

\begin{tabular}{|c|c|c|}
\hline Criteria & Definition & Scoring \\
\hline \multirow[t]{10}{*}{ Beighton [18] } & \multirow{2}{*}{$\begin{array}{l}\text { Passive hyperextension } \geq 10 \\
\text { degrees of the knee }\end{array}$} & Right - 1 point \\
\hline & & Left -1 point \\
\hline & \multirow{2}{*}{$\begin{array}{l}\text { Passive hyperextension } \geq 10 \\
\text { degrees of the elbow }\end{array}$} & Right - 1 point \\
\hline & & Left - 1 point \\
\hline & \multirow{2}{*}{$\begin{array}{l}\text { Passive apposition of the thumb } \\
\text { to the flexor aspect of the forearm }\end{array}$} & Right - 1 point \\
\hline & & Left - 1 point \\
\hline & \multirow{2}{*}{$\begin{array}{l}\text { Passive dorsiflexion of } 5^{\text {th }} \text { finger } \\
\text { metacarpophalangeal joint to } \geq 90^{\circ}\end{array}$} & Right - 1 point \\
\hline & & Left - 1 point \\
\hline & $\begin{array}{l}\text { Forward flexion of the trunk, } \\
\text { with the knees straight, } \\
\text { so that the palms rest easily } \\
\text { and flat on the floor }\end{array}$ & 1 point \\
\hline & $\begin{array}{l}{ }^{* *} \text { A score of } 4 / 9 \text { or greater } \\
\text { equates hypermobility }\end{array}$ & \\
\hline \multirow[t]{6}{*}{$\begin{array}{l}\text { Carter \& } \\
\text { Wilkinson [19] }\end{array}$} & $\begin{array}{l}\text { Bilateral passive apposition } \\
\text { of the thumb to } \\
\text { the flexor aspect of the forearm }\end{array}$ & 1 point \\
\hline & $\begin{array}{l}\text { Bilateral passive hyperextension } \\
\text { of the fingers to lie parallel } \\
\text { with the forearm }\end{array}$ & 1 point \\
\hline & $\begin{array}{l}\text { Passive hyperextension } \\
\text { of the elbows }>10^{\circ}\end{array}$ & 1 point \\
\hline & $\begin{array}{l}\text { Passive hyperextension } \\
\text { of the knees }>10^{\circ}\end{array}$ & 1 point \\
\hline & $\begin{array}{l}\text { Bilateral excessive passive } \\
\text { dorsiflexion of ankle } \\
\text { and excessive foot eversion }\end{array}$ & 1 point \\
\hline & \multicolumn{2}{|c|}{${ }^{* *}$ A score of $3 / 5$ or greater equates hypermobility } \\
\hline
\end{tabular}

average TP sensitivity (TP threshold score) and number of painful tender points (TP count) were computed. Pearson correlation coefficients were computed to assess the relationship between average VAS pain score, average TP score, and TP count. Average pain VAS and TP scores were compared between the $\mathrm{HM}+$ and $\mathrm{HM}$ groups using t-tests, and TP counts in the $\mathrm{HM}+$ versus HM- groups were compared using the non-parametric Mann-Whitney test (due to non-normal distributed data on TP counts).

\section{Results}

\section{Self-reported pain and pain sensitivity}

Among the 131 participants, the mean pain rating as measured by daily diaries on a 10-point VAS was 5.73 (SD 1.37). The mean TP count among all participants was 16.23 (SD 2.30) with $85 \%$ having 14 or more positive TPs. The mean TP score was $2.26 \mathrm{~kg} / \mathrm{cm}^{2}$ (SD 0.58) (Table 2). Among the $18 \mathrm{TP}$ sites, TP locations with the lowest mean pain threshold were in the head and neck region (anterior rib, low cervical, and occiput) with lower average thresholds consistently seen among the HM group (Figure 1A/B). In correlations between selfreported VAS and pain sensitivity measures based upon dolorimetry, neither TP score (Pearson $r=-0.08$ ) nor TP count (Spearman $\rho=0.06$ ) was significantly associated with VAS self-report of pain intensity (Table 3).

\section{Role of hypermobility in the pain experience}

Documentation of HM was available for 95\% (122/131) of participants. Of the 122 JFM patients, nearly half $(48 \%, \mathrm{n}=58)$ were noted by their primary rheumatologist to have hypermobile joints. Mean self-reported VAS in the HM+ group was 5.59 (SD 1.41) compared to 5.79 (SD 1.28) in the HM- group ( $\mathrm{p}=0.42$, not significant).

Table 2 Demographic information and mean pain scores (self-report VAS, tender point total and scores)

\begin{tabular}{lccc}
\hline Characteristic & Mean & SD $^{\mathbf{a}}$ & Range \\
\hline Age (years) & 15.08 & 1.81 & $11-18$ \\
VAS $^{\text {b }}$ Rating (0-10) & 5.73 & 1.37 & $1.16-8.86$ \\
Number of Positive Tender Points $^{c}(0-18)$ & 16.23 & 2.30 & $9-18$ \\
Tender Point Score (1-4 kg/ $\left.\mathrm{cm}^{2}\right)$ & 2.26 & 0.58 & \\
& Number & $\%$ & \\
\hline Female & 121 & 92.4 & \\
Male & 10 & 7.6 & \\
Race & & & \\
Caucasian & 117 & 89.3 & \\
Black or African-American & 9 & 6.9 & \\
Other & 5 & 3.8 & \\
\hline
\end{tabular}

${ }^{\mathrm{a}} \mathrm{SD}$ - standard deviation, ${ }^{\mathrm{b}}$ VAS - Visual Analogue Scale, ${ }^{\mathrm{c}}$ A positive tender point equates a dolorimetry score of $<4 \mathrm{~kg} / \mathrm{cm}^{2}$ of pressure. 

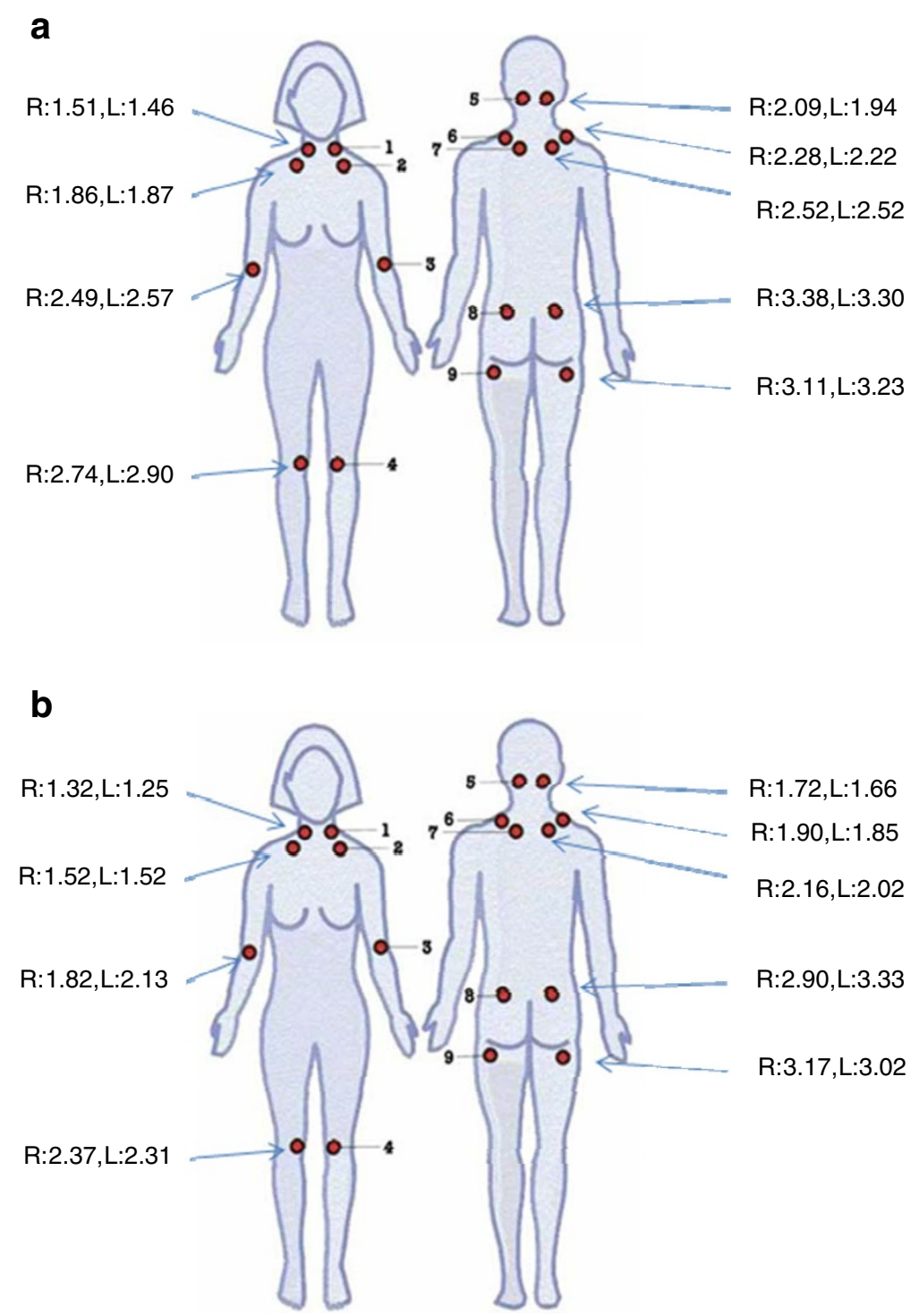

Figure 1 a. Tender point averages in JFM patients without joint HM. b. Tender point averages in JFM patients with joint HM. Legend Figure $1 \mathrm{a} / \mathrm{b}$. Distribution of mean threshold scores $\left(\mathrm{kg} / \mathrm{cm}^{2}\right)$ by tender point location. Mean tender point scores are noted for each of the 18 tender point sites. R: Right, L: Left, 1. Low Cervical, 2. Anterior Rib, 3. Lateral Epicondyle, 4. Medial Fat Pad, 5. Occiput, 6. Trapezius, 7. Supraspinatus, 8. External Outer Gluteal, 9. Greater Trochanter.

However, the $\mathrm{HM}+$ patients had significantly greater pain sensitivity with lower mean TP scores $\left(2.10 \mathrm{~kg} / \mathrm{cm}^{2}\right.$ vs. $\left.2.41 \mathrm{~kg} / \mathrm{cm}^{2}, \mathrm{p}=0.002\right)$ and higher TP count $(16.77$ vs. $15.72, \mathrm{p}=0.003$ ) than $\mathrm{HM}$ - patients (Table 4 ).

\section{Discussion}

Fibromyalgia syndrome in adolescents is characterized by chronic widespread musculoskeletal pain and multiple associated symptoms. Consistent with prior reports $[8,9]$, results of this study showed that joint HM commonly co-occurs with JFM in children and adolescents with nearly half of the adolescents with JFM also having HM. This is similar to findings from adult fibromyalgia studies which have reported that $46.6 \%$ [20] to $62 \%$ [10] of fibromyalgia patients also had HM. In addition to replicating findings regarding the overlap between JFM and HM, results of this study suggest the possibility that a 'benign' condition like joint laxity can be associated with enhanced pain sensitivity in JFM patients. Specifically, $\mathrm{HM}+$ patients show significantly greater physiologic sensitivity as measured by TP threshold and TP count than HM- patients, even though their self-report of clinical pain intensity did not differ. However, it is unclear if this difference is clinically relevant as all patients had relatively high pain sensitivity. Interestingly, all tender point locations were lower among the $\mathrm{HM}+$ group and not 
Table 3 Correlation analysis of the relationship between mean VAS pain score, tender point score, and tender point count

\begin{tabular}{lccc}
\hline & $\begin{array}{c}\text { Tender Point } \\
\text { Score }\end{array}$ & $\begin{array}{c}\text { Tender Point } \\
\text { Count }\end{array}$ & VAS Rating \\
\hline Tender Point Score & 1 & $-0.84^{\mathrm{b}}$ & -0.08 \\
Tender Point Count & $-0.84^{\mathrm{b}}$ & 1 & 0.06 \\
VAS $^{\mathrm{a}}$ Rating & -0.08 & 0.06 & 1 \\
\hline
\end{tabular}

${ }^{a}$ VAS - Visual Analogue Scale, ${ }^{b}$ p-value $<0.001$.

significantly different among areas that are typically flexible (i.e. knees).

Potential mechanisms underlying the relationship between HM and pain sensitivity in JFM patients might include genetic vulnerability associated with gene polymorphisms responsible for pain perception [21] [22], immunologic factors [23], or related to the common features of dysautonomia (syncope, orthostatic hypotension, tachycardia, etc.) often reported by both $\mathrm{HM}$ and JFM patients $[24,25]$. Interestingly, despite the evidence of increased pain sensitivity in JFM HM+ adolescents, we found that the subjective report of clinical pain (VAS pain ratings) did not correlate with physiologic pain sensitivity. Furthermore, there was no significant difference in clinical pain reports between JFM adolescents with and without HM. These results reinforce the notion that pain is a complex subjective multidimensional experience. Results obtained from different assessment methods (subjective pain ratings versus sensory testing) may therefore represent different facets of pain.

The results of this study have implications for the measurement of pain outcomes in clinical trials of JFM. In recent studies, cognitive behavioral therapy (CBT) has been found to be a promising treatment for JFM $[26,27]$ and the parent clinical trial associated with this study showed that CBT was effective in reducing painrelated disability and depressive symptoms. Patients also reported reduced pain intensity (VAS) levels, but there was no change in tender point sensitivity after CBT. In order to change physiologic pain sensitivity, other types of interventions, for example, intensive aerobic exercise programs, which have been shown to be effective for pain reduction [28] need to be further studied. Tailored programs for JFM HM+ children focusing on joint protection and strengthening might also be investigated to see if they can produce reductions in mechanical stress which could ameliorate heightened pain sensitivity.

We recognize several limitations of our study. Our patients were recruited from tertiary pediatric rheumatology clinics; therefore, they may represent the most severe and prolonged cases of JFM. The majority of patients $(85 \%, n=112)$ had a total of $>14$ positive TP
Table 4 Relationship of mean VAS score, tender point count and tender point score among JFM patients with or without joint hypermobility

\begin{tabular}{lcccc}
\hline & \multicolumn{3}{c}{ Hypermobility No Hypermobility } & \\
\cline { 2 - 3 } & Mean & Mean & $\mathbf{P}^{\mathbf{b}}$ & $\mathbf{C l}^{\mathbf{c}}$ \\
\hline VAS $^{\mathrm{a}}$ Rating & 5.59 & 5.79 & 0.42 & $-2.92-0.68$ \\
Tender Point Count & 16.77 & 15.72 & $0.003-1.9--0.24$ \\
Tender Point Score & 2.10 & 2.41 & 0.002 & $0.12-0.52$ \\
\hline a VAS - Visual Analogue Scale, ${ }^{\mathrm{b}}$ - Significant $\mathrm{p}$-value $<0.05,{ }^{\mathrm{c}}$ - Confidence \\
Interval.
\end{tabular}

and nearly half (47\%) had 18/18 positive TP. Another limitation is that the scoring systems for HM (i.e. Beighton, Brighton, Carter and Wilkinson) were not strictly standardized in our study; however, each rheumatologist indicated they documented hypermobility if a patient met criteria. Despite the potential recruitment of patients with more severe JFM and the nonstandardized clinician assessment of HM, the prevalence of $\mathrm{HM}$ in this sample was found to be similar to that reported by Siegel and colleagues, i.e., almost half of the JFM sample [9].

\section{Conclusions}

The findings of this study strengthen prior reports of joint HM being commonly observed among clinical populations of adolescent JFM patients. Additionally, we found that HM is associated with heightened pain sensitivity. Suggestions for future research include identifying the genetic link(s) attributable to these associated conditions, continued physiological assessments to better understand the mechanisms of pain in both HM and JFM, and evaluation of targeted exercise programs for this population. A greater understanding of the various aspects of pain in JFM is needed to further enrich the multidisciplinary approach for treatment of this complex syndrome.

Competing interests

The authors declare that they have no competing interests.

\section{Authors' contributions}

$\Pi T$ conceived of the study, and participated in its design and coordination, acquisition of data, analysis and data interpretation and helped to draft the manuscript. AD participated in data entry as well as performed the statistical analysis. KS participated in acquisition of data and interpretation. SS participated in acquisition of data and interpretation. $\mathrm{PH}$ participated in acquisition of data and interpretation. SKZ conceived of the study, and participated in its design and coordination and helped to draft the manuscript. All authors read and approved the final manuscript.

\section{Acknowledgements}

We would like to thank Dr. Brent Graham and Dr. Murray Passo for their help with patient recruitment and data collection.

Funding

This work was supported by a grant from the National Institute of Arthritis and Musculoskeletal and Skin Diseases [Grant \# R01 AR050028].

\section{Author details}

'Division of Rheumatology, MLC 4010, Cincinnati Children's Hospital Medical Center, 3333 Burnet Avenue, Cincinnati, OH 45229, USA. ${ }^{2}$ Pediatric 
Rheumatology Unit, Shaare Zedek Medical Center, Jerusalem, Israel. ${ }^{3}$ Division of Pediatric Rheumatology, University of Louisville, Louisville, KY, USA. ${ }^{4}$ Division of Behavioral Medicine and Clinical Psychology, Cincinnati Children's Hospital Medical Center, Cincinnati, OH, USA. ${ }^{5}$ Center of Pediatric Rheumatology, Cleveland Clinic, Cincinnati, OH, USA.

Received: 18 January 2012 Accepted: 4 June 2012

Published: 15 June 2012

\section{References}

1. Buskila D, Press J, Gedalia A, Klein M, Neumann L, Boehm R, Sukenik S: Assessment of nonarticular tenderness and prevalence of fibromyalgia in children. J Rheumatol 1993, 20(2):368-370.

2. Buskila D, Neumann L, Hershman E, Gedalia A, Press J, Sukenik S: Fibromyalgia syndrome in children: An outcome study. J Rheumatol 1995, 22(3):525-528.

3. Yunus MB, Masi AT, Aldag JC: Preliminary criteria for primary fibromyalgia syndrome (PFS): multivariate analysis of a consecutive series of PFS, other pain patients, and normal subjects. Clin Exp Rheumatol 1989, 7(1):63-69.

4. Wolfe F, Smythe HA, Yunus MB, Bennett RM, Bombardier C, Goldenberg DL, Tugwell P, Campbell SM, Abeles M, Clark P, et al: The American College of Rheumatology 1990 Criteria for the Classification of Fibromyalgia. Report of the Multicenter Criteria Committee. Arthritis Rheum 1990, 33(2):160-172.

5. Wahezi DM, llowite N: Joint problems and hypermobility. Pediatr Rev 2009, 30(5):187-189.

6. Sacheti A, Szemere J, Bernstein B, Tafas T, Schechter N, Tsipouras P: Chronic pain is a manifestation of the Ehlers-Danlos syndrome. J Pain Symptom Manage 1997, 14:88-93.

7. Leone $\mathrm{V}$, Tornese $\mathrm{G}$, Zerial $\mathrm{M}$, Locatelli $\mathrm{C}$, Ciambra R, Bensa M, Pocecco M: Joint hypermobility and its relationship to musculoskeletal pain in schoolchildren: a cross-sectional study. Arch Dis Child 2009, 94(8):627-632.

8. Gedalia A, Press J, Klein M, Buskila D: Joint hypermobility and fibromyalgia in schoolchildren. Ann Rheum Dis 1993, 52(7):494-496.

9. Siegel DM, Janeway D, Baum J: Fibromyalgia syndrome in children and adolescents: Clinical features at presentation and status at follow-up. Pediatrics 1998, 101(3 Pt 1):377-382.

10. Ofluoglu D, Gunduz OH, Kul-Panza E, Guven Z: Hypermobility in women with fibromyalgia syndrome. Clin Rheumatol 2006, 25(3):291-293.

11. Meeus M, Nijs J: Central sensitization: a biopsychosocial explanation for chronic widespread pain in patients with fibromyalgia and chronic fatigue syndrome. Clin Rheumatol 2007, 26(4):465-473.

12. Staud R, Craggs JG, Robinson ME, Perlstein WM, Price DD: Brain activity related to temporal summation of C-fiber evoked pain. Pain 2007, 129(1-2):130-142.

13. Grahame R: Pain, distress and joint hyperlaxity. Joint Bone Spine 2000, 67(3):157-163

14. Kashikar-Zuck S, Ting TV, Arnold LM, Bean J, Powers SW, Graham TB, Passo MH, Schikler KN, Hashkes PJ, Spalding S, et al: Cognitive behavioral therapy for the treatment of juvenile fibromyalgia: a multisite, single-blind, randomized, controlled clinical trial. Arthritis Rheum 2012, 64(1):297-305.

15. Adib N, Davies K, Grahame R, Woo P, Murray KJ: Joint hypermobility syndrome in childhood. A not so benign multisystem disorder? Rheumatology (Oxford) 2005, 44(6):744-750.

16. McGrath PJ, Walco GA, Turk DC, Dworkin RH, Brown MT, Davidson K, Eccleston C, Finley GA, Goldschneider K, Haverkos L, et al: Core outcome domains and measures for pediatric acute and chronic/recurrent pain clinical trials: PedIMMPACT recommendations. J Pain 2008, 9(9):771-783.

17. Finley AG, McGrath PJ: Progress in pain research and management, Volume 10. Seattle, WA: IASP Press; 1998.

18. Beighton P, Solomon L, Soskolne CL: Articular mobility in an African population. Ann Rheum Dis 1973, 32(5):413-418.

19. Carter C, Wilkinson J: Persistent Joint Laxity and Congenital Dislocation of the Hip. J Bone Joint Surg Br 1964, 46:40-45.

20. Sendur OF, Gurer G, Bozbas GT: The frequency of hypermobility and its relationship with clinical findings of fibromyalgia patients. Clin Rheumatol 2007, 26(4):485-487.

21. Cohen H, Neumann L, Glazer Y, Ebstein RP, Buskila D: The relationship between a common catechol-O-methyltransferase (COMT) polymorphism val(158) met and fibromyalgia. Clin Exp Rheumatol 2009, 27(5 Suppl 56):S51-S56.
22. Vargas-Alarcon G, Fragoso JM, Cruz-Robles D, Vargas A, Lao-Villadoniga J, Garcia-Fructuoso F, Ramos-Kuri M, Hernandez F, Springall R, Bojalil R, et al: Catechol-O-methyltransferase gene haplotypes in Mexican and Spanish patients with fibromyalgia. Arthritis Res Ther 2007, 9(5):R110.

23. Bennett RM, Cook DM, Clark SR, Burckhardt CS, Campbell SM: Hypothalamic-pituitary-insulin-like growth factor-I axis dysfunction in patients with fibromyalgia. J Rheumatol 1997, 24(7):1384-1389.

24. Gazit Y, Nahir AM, Grahame R, Jacob G: Dysautonomia in the joint hypermobility syndrome. Am J Med 2003, 115(1):33-40.

25. Di Franco M, lannuccelli C, Alessandri C, Paradiso M, Riccieri V, Libri F, Valesini G: Autonomic dysfunction and neuropeptide $\mathrm{Y}$ in fibromyalgia. Clin Exp Rheumatol 2009, 27(5 Suppl 56):S75-S78.

26. Kashikar-Zuck S, Swain NF, Jones BA, Graham TB: Efficacy of cognitivebehavioral intervention for juvenile primary fibromyalgia syndrome. J Rheumatol 2005, 32(8):1594-1602.

27. Degotardi PJ, Klass ES, Rosenberg BS, Fox DG, Gallelli KA, Gottlieb BS: Development and evaluation of a cognitive-behavioral intervention for juvenile fibromyalgia. J Pediatr Psychol 2006, 31(7):714-723.

28. Stephens S, Feldman BM, Bradley N, Schneiderman J, Wright V, SinghGrewal D, Lefebvre A, Benseler SM, Cameron B, Laxer R, et al: Feasibility and effectiveness of an aerobic exercise program in children with fibromyalgia: results of a randomized controlled pilot trial. Arthritis Rheum 2008, 59(10):1399-1406.

\section{doi:10.1186/1546-0096-10-16}

Cite this article as: Ting et al:: The role of benign joint hypermobility in the pain experience in Juvenile Fibromyalgia: an observational study. Pediatric Rheumatology 2012 10:16.

\section{Submit your next manuscript to BioMed Central and take full advantage of:}

- Convenient online submission

- Thorough peer review

- No space constraints or color figure charges

- Immediate publication on acceptance

- Inclusion in PubMed, CAS, Scopus and Google Scholar

- Research which is freely available for redistribution 